\title{
The Contribution of Stress Level in Modifying the Cardiometabolic Risk in a Population Cohort from North-East Romania
}

\author{
TIBERIU LUNGULEAC ${ }^{1}$, DOINA AZOICAI2*, ALINA MANOLE², ALEXANDRU PATRASCU 4 , MIHAELA MOSCALU² \\ ${ }^{1}$ Grigore T. Popa University of Medicine and Pharmacy, Faculty of Medicine, Thoracic Surgery Department, 16 Universitatii Str., \\ 700115, Iasi, Romania \\ ${ }^{2}$ Grigore T. Popa University of Medicine and Pharmacy, Faculty of Medicine, Epidemiology Department, 16 Universitatii Str., \\ 700115, lasi, Romania \\ ${ }^{3}$ Grigore T. Popa University of Medicine and Pharmacy, Faculty of Medicine, Medical Informatics and Biostatistics Department, \\ 16 Universitatii Str., 700115, Iasi, Romania \\ ${ }^{4}$ Grigore T. Popa University of Medicine and Pharmacy, Faculty of Medicine, Orthopaedic Department, 16 Universitatii Str., \\ 700115, lasi, Romania
}

\begin{abstract}
The cardiometabolic risk is used to assess the probability of developing a cardiovascular disease in association with diabetes. The research of stress factor represents a breakthrough in assessing this risk. The study aim was to evaluate the importance of cardiometabolic risk measurement instruments in the context of psychobehavioral factors expressed by individual stress level. The cross-sectional study consisted of applying a PSL assessment questionnaire to a group of 254 individuals. Quantification of the PSL was achieved by a previously validated standardized questionnaire (PSS Scale). The research involved completing the questionnaire and corroborating clinical and paraclinical data (LDL-cholesterol, glycemia, glycosylatedhemoglobin - HbAlc). Data were analyzed using the SPSS V.21 software (IBM). The calculation of global cardiovascular risk score (SCORE) highlighted that $75 \%$ of cases presented a risk for a cardiovascular event over the next 10 years of lower than 3 (30\%). Fasting glycemia values showed significant differences compared to glycosylated hemoglobin values $(t=8.68, p<<0.01,95 \% \mathrm{Cl})$. It is noted the absence of significant differences between the calculated mean value and the normal $L D L$ maximum threshold ( $t_{\text {value }}=0.96, p=0.336$ ). Mean values of females perceived stress score $\left(M_{\text {pssffemale }}=20.9 \pm 6.43 \mathrm{SD}\right)$ are significantly higher $(F=$ $30.7, p<0.05,95 \% \mathrm{Cl})$ versus males $\left(M_{\text {pss }}=16.5 \pm 5.92 \mathrm{SD}\right)$, but there is no correlation between patient's age and perceived stress score $r$ PS $r$ male $=0.028, p=0.651,95 \% \mathrm{Cl})$. Correlation of socio-economic factors with PSL reveals that low educational level $(r=-0.203, p=0.001)$ and low income $(r=-0.204, p=$ $0.001)$ significantly increase the PSL. The results indicate that there is no correlation between perceived stress score and cardiovascular risk score $(r=-0.0936, p=0.137,95 \% \mathrm{Cl})$. Aspects revealed by study results highlight the need for monitoring stress factor in actions of clinical management in patients at high cardiometabolic risk.
\end{abstract}

Keywords: cardiometabolic risk, psycho-behavioral factors, perceived stress scale

Risk factors represent variables associated with an increased risk of disease [1]. A risk factor is a characteristic or an exposure of an individual that increases the possibility of developing a medical condition. Cardiometabolic risk is influenced by various, modifiable or non-modifiable elements, physiological (age, gender), pathological (dyslipidemia) related to the individual, his or her pattern and the environment.

Arterial hypertension, tobacco smoking, hyperglycemia, sedentary lifestyle, and obesity are established risk factors which increase the risk of cardiovascular diseases, diabetes mellitus, and neoplasias [2]. There are also recently studied risk factors recognized in present, specific to modern life, among which the level of stress perceived by an individual should be taken into consideration [3].

Cardiometabolic risk may be defined as the total factors of probability, associated with the cardiovascular condition and the risk of type 2 diabetes mellitus [4], in contrast to the classic cardiovascular risk that defines the probability of developing atherosclerotic disease clinically or subclinically manifested such as coronary disease, cerebrovascular disease, peripheral arterial disease, aortic aneurysm [5].

The concept of cardiometabolic risk highlights the importance of comprehensive assessment of cardiovascular risk and those which predict the development of type 2 diabetes [6], especially when cardiometabolic risk precedes both type 2 diabetes and cardiovascular disease and influences their evolution and prognosis.

The Perceived Stress Scale (PSS) is a psychological instrument for measuring the level of stress experienced personally by the individual at risk. It is a measure of the degree of which situations in a person's life are estimated to have an effect in generating imbalances in the body's homeostasis. The questions contained in this scale of evaluation were designed to assess how respondents perceive that their lives are influenced by unpredictable, difficult to control events that overstress.

The study aimed to assess the importance of instruments that allow a quantification of cardiometabolic risk by taking into account the psycho-behavioral factors expressed by the individual stress level.

\section{Experimental part}

Materials and methods

The cross-sectional study consisted of applying a questionnaire of stress assessment to a group of 254 individuals who accepted the participation by signing the informed consent. The quantification of perceived stress level (stress scores) was achieved with a previously validated tool, PSS Scale (The PSS Scale, reprinted with 
$0=$ Never $1=$ Almost never 2 = Sometimes $3=$ Fairly often $4=$ Very often

1. In the last month, how often have you been upset because of something that $\quad \begin{array}{llllll} & 0 & 1 & 2 & 3 & 4\end{array}$ happened unexpectedly?

2. In the last month, how often have you felt that you were unable to control the important things in your life?

3. In the last month, how often have you felt nervous and "stressed"?

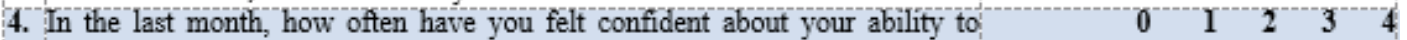
handle your personal problems?

5. In the last month, how often have you felt that things were going your way?

6. In the last month, how often have you found that you could not cope with all the things that you had to do?

7. In the last month, how often have you been able to control imitations in your life?

8. In the last month, how often have you felt that you were on top of things?

9. In the last month, how often have you been angered because of things that were outside of your control?

10. In the last month, how often have you felt difficulties were piling up so high that you could not overcome them?

OVERALL SCORE:

\begin{tabular}{|l|l|l|}
\hline Overall score & Stress level is perceived: & Health concern: \\
\hline $0-7$ & Much lower than average & Very low \\
\hline $8-11$ & Slightly lower than average & Low \\
\hline $12-15$ & Average & Average \\
\hline $16-20$ & Slightly higher than average & High \\
\hline Over 21 & Much higher than average & Very high \\
\hline
\end{tabular}

Table 2

PERCEIVED STRESS SCALE
Table 1

THE ASSESSMENT OF

PERCEIVED STRESS

SCOREQUESTIONNAIRE

(PSS)

permission of the American Sociological Association, from Cohen, S., Kamarck, T., Mermelstein, R. (1983). [7] (table $1,2)$.

The questions in this scale ask you about your feelings and thoughts during the last month. In each case, you will be asked to indicate by circling how often you felt or thought a certain way.

Higher values of perceived stress score are associated with higher levels of stress and indicate a greater probability that it interferes with aspects such as lifestyle changes (a person's efforts to quitsmoking) and their ability to improve the quality of life. The research involved analyzing the information obtained by completing the questionnaire and corroborating the clinical and paraclinical data (LDLcholesterol, fasting glycemia, glycosylatedhemoglobin HbAlc). The data were analyzed using the SPSS V.21 software (IBM).

The differences between the parameters analyzed by the involved grouping variables (independent variables) were tested using specific tests according to the type and characteristics of the data, OneWayAnova and Kruskal Wallis test, respectively. The homogeneity of the studied parameters evaluated in terms of dispersion (normal distributions) was highlighted by Levene test results ( $p>$ $0.05,95 \% \mathrm{Cl}$ ). For comparative analysis, the OneWayAnova test $(95 \% \mathrm{Cl})$, also known as dispersion analysis or variance analysis, was applied. The significance level ( $p$-value) was considered to be $0.05(5 \%)$, for a $95 \%$ confidence interval, indicating that the decision is fair. The Chi-square test was applied to non-parametric analysis. The Yates correction (continuity corrected chi-square) has been applied to less than 5 elements.

\section{Results and discussions}

\section{Demographic aspects of the study group}

The group distribution was homogeneous, $59.8 \%$ being male, and $40.16 \%$ women. Furthermore, a normal distribution of cases in terms of age was observed, the maximum frequency of cases being the age group of 6170 years (21.65\%) (fig. 1 ). The mean age in the analyzed group was $54.8 \pm 16.3 \mathrm{SD}$, with no significant differences between the two groups of patients ( $M$ ageffemale $=55 \pm 16.9$ $\left.\mathrm{SD} ; \mathrm{M}_{\text {age/male }}=55 \pm 16.9 \mathrm{SD}\right)(\mathrm{F}=0.04, \mathrm{p}=0.824)$.

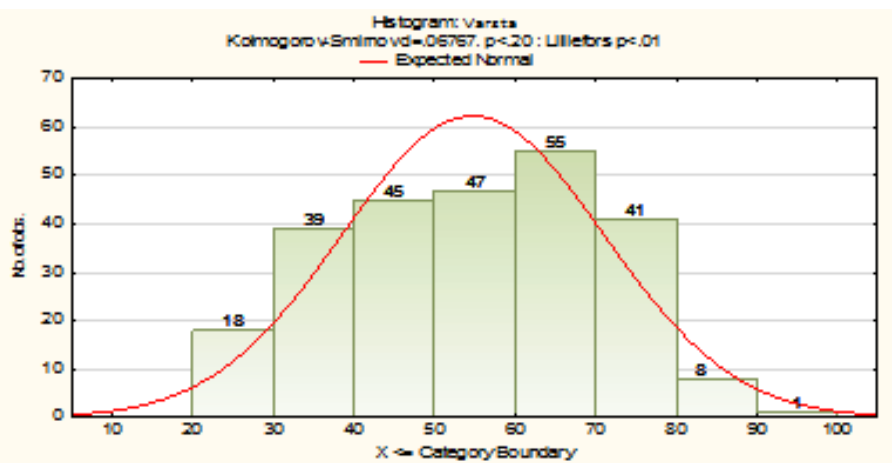

Fig. 1.Age histogram in the study group

\section{Socio-economic aspects}

Risk factors with increased potential for influencing the cardiometabolic risk were: occupation - agriculture $(29.9 \%)$, secondary education (56.3\%), and average income per family member ranging between 100-400 RON (53.9\%).

\section{Lifestyle and cardiometabolic risk factors \\ Tobacco smoking}

Non-smoking patients accounted for $77.1 \%$ of the study group cases.

\section{Lifestyle - watching TV}

Patients allocated the highest rate of viewing on TV 1-2 hours / day (44.5\%) or less than $1 \mathrm{~h} /$ day (26.8\%).

Global cardiovascular risk score

The evaluation of the cardiovascular risk score indicates that $75 \%$ of the cases of the analyzed group (Q75) presented a risk for the cardiovascular event over the next 10 years less than $3(30 \%)$, and even lower than $60 \%$ in $2.52 \%$ of cases (table 3 ).

Lipid profile - LDL-cholesterol

The normal values were considered $<110 \mathrm{mg} / \mathrm{dL}$. The mean LDL-cholesterol value was $112.1 \mathrm{mg} / \mathrm{dL} \pm 35.1 \mathrm{SD}$ with a minimum of $8.2 \mathrm{mg} / \mathrm{dL}$ and a maximum of 233.6 $\mathrm{mg} / \mathrm{dL}$. There was no significant differences between the calculated mean value and the normal LDL maximum threshold ( $\mathrm{t}_{\text {value }}=0.96, \mathrm{p}=0.336$ ). Frequency distribution 


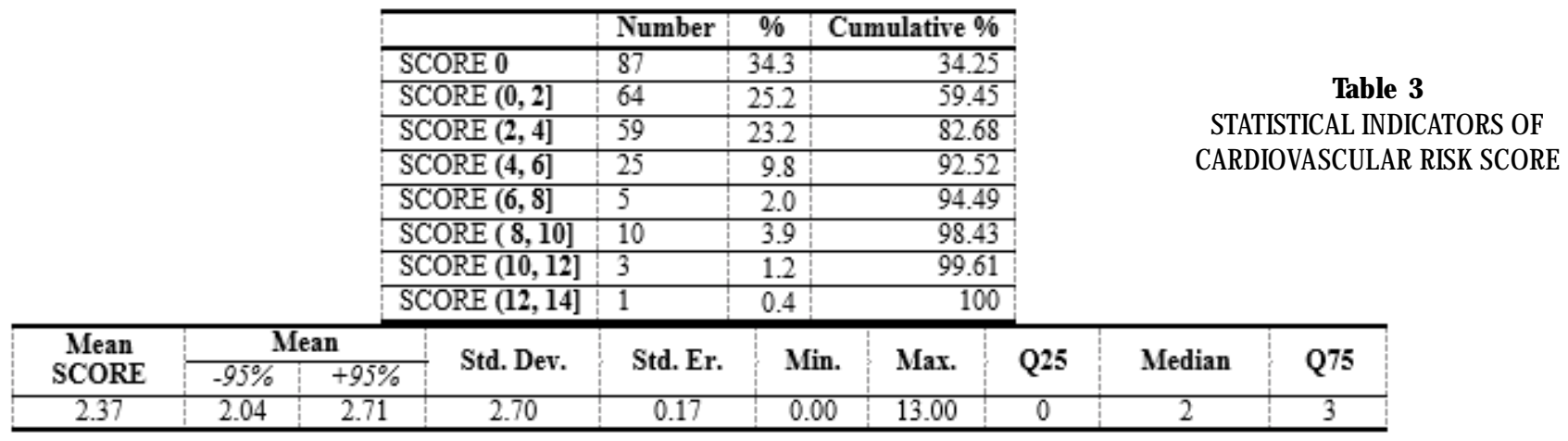

indicated that $50 \%$ of cases had LDL values lower than $110 \mathrm{mg} / \mathrm{dL}, 1.6 \%$ of patients having values higher than $200 \mathrm{mg} / \mathrm{dL}$.

The assessment of diabetes risk

Normal values of fasting glycemia were considered to be lower than $110 \mathrm{mg} / \mathrm{dL}$, modified basal glycemia was considered for values ranging from $110-126 \mathrm{mg} / \mathrm{dL}$, and diabetes diagnosis considered for fasting glycemia values over $126 \mathrm{mg} / \mathrm{dL}$.

For metabolic syndrome, values higher than $100 \mathrm{mg} /$ $\mathrm{dL}$ were considered. The mean fasting glycemia value was $112 \mathrm{mg} / \mathrm{dL} \pm 32.2 \mathrm{SD}$, with a minimum of $57 \mathrm{mg} / \mathrm{dL}$ and a maximum of $371 \mathrm{mg} / \mathrm{dL}$. In the studied group, $75 \%$ of cases had values lower than $115 \mathrm{mg} / \mathrm{dL}$. The fasting glycemia values recorded in the study group did not show significant differences compared to the normal value of fasting glycemia maximum threshold ( $t_{\text {value }}=0.99, p=0.32$ ).

The normal values of glycosylated hemoglobin were considered to be the lowest of 5.4\%, and the "gray area" was considered to be in the range $(5.4 \%, 5.7 \%]$. The values corresponding to the cardiovascular risk were considered in the range $(5.7 \%, 6.5 \%]$, and diabetes mellitus was considered for glycosylated hemoglobin values higher than $6.5 \%$. The mean value of glycosylated hemoglobin was $5.9 \% \pm 0.9 \mathrm{SD}$, with a minimum of $4.9 \%$ and a maximum of $12.6 \%$. In the studied group, $75 \%$ of cases presented values lower than $5.9 \%$.

The fasting glycemia values recorded in the study group showed significant differences compared to the normal maximum threshold value of glycosylated hemoglobin ( $t_{\text {value }}$ $=8.68, \mathrm{p}<<0.01,95 \% \mathrm{Cl}$ ).
Stress score (PSS SCALE)

The assessment of health concern based on the perceived stress level was performed with the PSS scale (table 4, fig. 2).

The results indicated a high frequency of cases of very high health concern (43.3\%), while for $3.9 \%$ of cases health concern reached minimum levels.

The assessment of the correlation between perceived stress level and cardiometabolic risk factors

The results of the study indicated a significantcorrelation $(\div 2=36.27, p<<0.01,95 \% \mathrm{Cl})$ between the patients' gender and the perceived stress score (table 5).

Mean values of female perceived stress score $\left(M_{\text {PsSffemale }}\right.$ $=20.9 \pm 6.43 S \mathrm{~S})$ are significantly higher $(\mathrm{F}=30.7, \mathrm{p}$, $<<$ $0.05,95 \% \mathrm{Cl}$ ) compared to male perceived stress levels $\left(M_{\text {pss } / \text { male }}=16.5 \pm 5.92 \mathrm{SD}\right)$. The value series in the two studuled groups were homogeneous $\left(F_{\text {Levene }}=1.35, p=\right.$ 0.24) (fig.3).

The correlation of the socio-economic factors with the perceived stress score reveals that the educational level and the average income per family member significantly influence the perceived stress score, the low educational level $(r=-0.203, p=0.001)$ and the low income $(r=$ $0.204, p=0.001$ ) significantly increase the perceived stress score (table 6).

The influence of the perceived stress level on the cardiometabolic risk factors was assessed usinf the analysis of the ROC (Receiver Operator characteristic Curve). The analysis showed a significant predisposition for elevated perceived stress scores in female patients, the results showed significant AUC (Area under curve)

\begin{tabular}{|l|l|l|r|r|}
\hline Overall Score & The level of stress is perceived: & Health Concern: & $\mathbf{N = 2 5 4}$ & $\%$ \\
\hline $0-7$ & Much lower than average & Very low & 10 & 3.9 \\
\hline $8-11$ & Slightly lower than average & Low & 23 & 9.1 \\
\hline $12-15$ & Average & Average & 39 & 15.4 \\
\hline $16-20$ & Slightly higher than average & High & 72 & 28.3 \\
\hline over 21 & Much higher than average & Very high & 110 & 43.3 \\
\hline
\end{tabular}

Table 4

THE ASSESSMENT OF PERCEIVED STRESS LEVEL

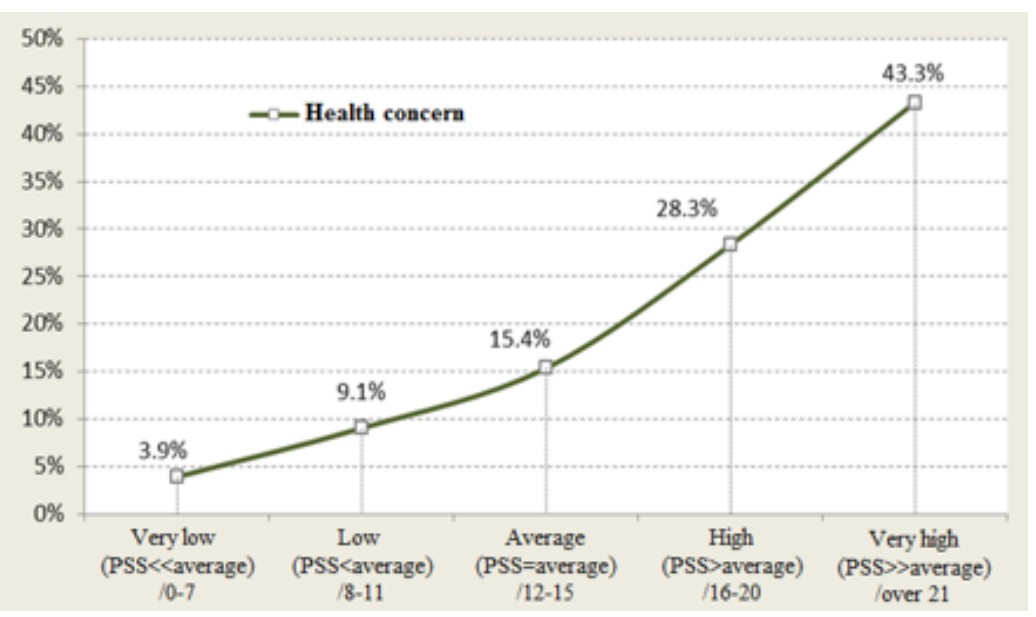

REV.CHIM.(Bucharest) $\bullet 70$ No. $3 \bullet 2019$

http://www.revistadechimie.ro 


\begin{tabular}{|l|c|c|}
\hline \multicolumn{1}{|c|}{$\mathbf{d f}=\mathbf{4}$} & Chi-square $\boldsymbol{\chi}^{\mathbf{2}}$ & $\begin{array}{c}\mathrm{p} \\
\mathbf{9 5 \%} \text { confidence interval }\end{array}$ \\
\hline Pearson Chi-pătrat $-\boldsymbol{\chi}^{2}$ & 36.27108 & $\mathrm{p}=.00000$ \\
\hline M-L Chi-square & 36.85241 & $\mathrm{p}=.00000$ \\
\hline Correlation coefficient (Spearman Rank R) & -.479308 & $\mathrm{p}=.00000$ \\
\hline
\end{tabular}

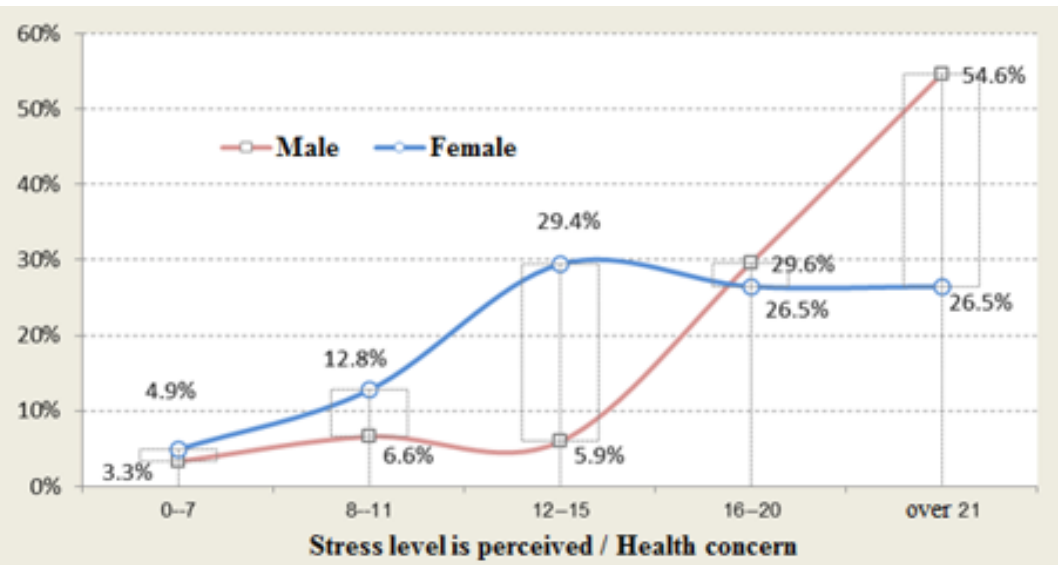

\begin{tabular}{|l|c|c|}
\hline Perceived stress score & r - correlation coefficient & p-value significance level \\
\hline Occupation & .0147 & 0.816 \\
\hline Educational level & -.2036 & 0.001 \\
\hline Average income / family member & -.2042 & 0.001 \\
\hline
\end{tabular}

Table 5

ESTIMATED PARAMETERS IN TESTING THE CORRELATION OF PERCEIVED STRESS LEVEL VS. M / F

Fig. 3.Perceived stress level by groups (M/F) values $\left(\mathrm{AUC}_{\text {fem }}=0.706, \mathrm{p}<0.01,95 \% \mathrm{Cl}: \mathrm{AUC} \rightarrow 0.642-\right.$ 0.770 ).

Mean age values did not show significant differences depending on the patients perceived stress level $(F=2.36$, $p=0.0537,95 \% \mathrm{Cl}$ ), the age being homogeneous for the studied stress levels. No correlation was observed between patient age and perceived stress score $(r=0.028, p=$ $0.651,95 \% \mathrm{Cl}$ ).

SCORE values are nothomogeneous depending on the perceived stress level $(F=5.12, p=0.0005)$. Thus, for the comparison of the SCORE values, the results of the KruskalWallis non-parametric analysis were taken into account, indicating the absence of significant differences between SCORE values according to perceived stress level $(F=$ $7.6, p=0.107)$. The results indicated that there was no correlation between perceived stress score and cardiovascular risk score $(r=-0.0936, p=0.137,95 \% \mathrm{Cl})$ (fig. 4).

Predictability is low in the perceived stress score on cardiovascular risk score, with non-significant AUC values (AUC $_{\text {score }}=0.482, p=0.284,95 \% \mathrm{Cl}: \mathrm{AUC}^{\prime} ! 0.411-0.553$ ).

LDL values are homogeneous according to the perceived stress level $(F=1.174, p=0.951)$, with no significant differences depending on PSS ( $F=1.15, p=$ 0.331 ). The analysis results indicated that there is no correlation between perceived stress score and LDL values

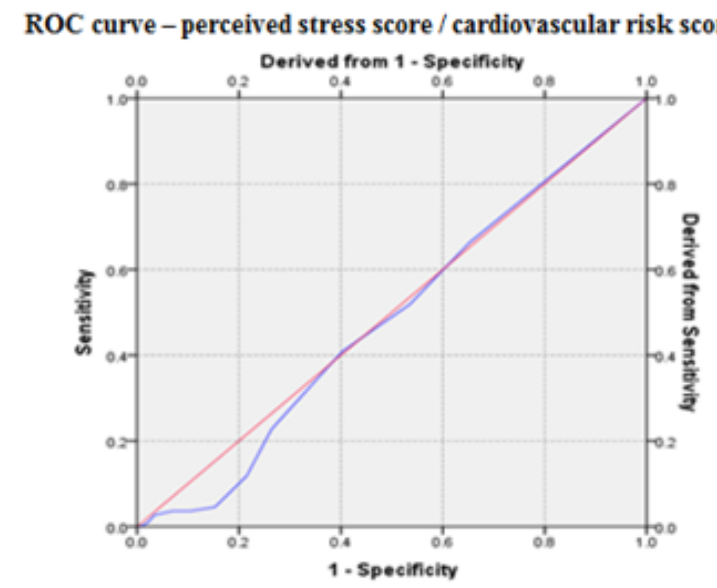

Fig. 4. ROC curve on PSS prediction vs. SCORE
( $r=0.057, p=0.364,95 \% \mathrm{Cl}$ ). The results lead to the conclusion that there is no question of predictability of the perceived stress score on LDL values, with non-significant AUC values (AUC $C_{L D L}=0.438, p=0.124,95 \% \mathrm{Cl}$ : AUC $\rightarrow$ 0.360-0.516).

The fasting glycemia values are not homogeneous depending on the perceived stress level $(F=3.501, p=$ $0.008)$. Thus, the non-parametric analysis indicated the presence of significant differences depending on the perceived stress level $(F=35.71, p<<0.01)$. The analysis results indicated that there is a significant correlation between the perceived stress score and the glycemia values $(r=0.272, p<0.01,95 \% \mathrm{Cl})$. The results lead to the conclusion that the perceived stress score has significant predictive power on the glycemia values, with significant AUC values ( $A \cup C_{\text {fasting }}=0.715, p<0.01,95 \% \mathrm{Cl}$ : AUC $\rightarrow 0.653-0.777$ ) (tabable 7).

The values of perceived stress score may be considered as predictive on glycosylated hemoglobin ( $\mathrm{HbAlc}$ ), AUC (AUC ${ }_{\text {HbAIC }}=0.656, p<0.01,95 \% \mathrm{Cl}: \mathrm{AUC} \rightarrow 0.590-0.722$ ). The analysis results indicated that there was no correlation between perceived stress score and glycosylated hemoglobin values $(r=0.057, p=0.364,95 \% \mathrm{Cl}$ ) (table 8).

Studies attested the long-time correlation between stress and cardiovascular diseases. There are ambiguities about the underlying mechanisms. A number of theories have been proposed, including autonomic nervous system hyperactivity and humoral changes that cause endothelial dysfunction. The proinflammatory status associated with the oxidative imbalance is key physiopathological components of stress-induced cardiovascular changes [8] .

A study conducted in Croatia on 300 patients (131 women and 169 men, median age 53.5 years) with uncomplicated arterial hypertension, attempted to determine the relationship between the adherence to antihypertensive drug therapy and stress perception, depression, arterial hypertension and myocardial infarction. The perceived incapacity in the process of stress control and negative thoughts/emotions represented factors that decrease the adherence to antihypertensive treatment [9].

Occupational stress predisposes to cardiometabolic disease, research showing that individuals who have spent 
Table7

ESTIMATED PARAMETERS IN ROC CURVE ANALYSIS ON PERCEIVED STRESS SCORE VSFASTING GLYCEMIA

\begin{tabular}{|c|c|c|c|c|c|}
\hline \multicolumn{6}{|c|}{ Area under ROC curve } \\
\hline \multirow{2}{*}{$\begin{array}{l}\text { Tested variables } \\
\text { Cardiometabolic risk factors }\end{array}$} & \multirow{2}{*}{$\begin{array}{c}\text { Area Under } \\
\text { Curve } \\
\text { (AUC) }\end{array}$} & \multirow{2}{*}{$\begin{array}{l}\text { Standard } \\
\text { error }\end{array}$} & \multirow{2}{*}{$\begin{array}{c}\text { Significance } \\
\text { level }^{\mathrm{b}} \\
\text { (p) }\end{array}$} & \multicolumn{2}{|c|}{$\begin{array}{c}\text { AUC } \\
95 \% \text { Confidence interval }\end{array}$} \\
\hline & & & & Inf. limit & Sup. limit \\
\hline Fasting glycemia & .715 & .032 & .000 & .653 & .777 \\
\hline
\end{tabular}

\section{Table8}

\begin{tabular}{|l|l|}
\hline $\mathbf{r}$-correlation coefficient & p-value significance level \\
\hline
\end{tabular} HbAlc ws.Stress score 0.2167 0.001

THE MEAN VALUES OF HbAlc VS. THE PERCEIVED STRESS LEVEL

more than 10 years working in shifts, have been prone to develop symptoms of metabolic syndrome compared to those without exposure to shift work, even after adjustments for age and sex [10].

An observational study of 1878 Saudi students admitted to university identified that $44.4 \%$ of them had a stress score over 27. The prevalence of this score was higher in women than in men ( $49.7 \%$ versus $40.7 \%)$. The prevalence of obesity, arterial hypertension and dyslipidemia was significantly higher in males than in females [11].

A research highlighted the idea that exhaustion is a risk factor for cardiovascular diseases by sympathetic and parasympathetic systems and the hypothalamic-pituitaryadrenal axis disorder. The study was conducted on 55 subjects, 34 men and 21 women diagnosed with burnout syndrome and 40 healthy subjects, 16 men and 24 women. After exposed to stressful situations, the clinical physiological parameters such as blood pressure and heart rate, and paraclinical parameters (the ejection fraction), as well as hormonal concentrations, such as serum cortisol levels were determined. Stress response has been shown to be ineffective in subjects previously diagnosed with burnout syndrome [12].

A systematic review that included 39 prospective cohort studies demonstrates a significant correlation between the chronic psychosocial stress and the development of metabolic syndrome. The analysis was individualized and each component of metabolic syndrome was evaluated, how ever, the shortcoming of the the study was represented by the limited quantity of available research studies and their heterogeneity [13].

According to an American study conducted in 2013 on 24,443 participants, high stress level was reported by 3529 low-income people $(35.4 \%)$ as compared to those with a high income $(22.1 \%)$, higher risk of death being also observed in low income individuals [14].

A North American study performed in 2014, on 5313 men and women aged 18 to 74 years, examined several stress indicators (chronic, perceived, and traumatic) in relation to the prevalence of coronary artery disease, stroke and major risk factors for cardiovascular diseases, major risk factors in a Hispanic community. Chronic stress was significantly associated with an increased prevalence of coronary artery disease, stroke, diabetes and arterial hypertension. Perceived stress was correlated with an increased prevalence of tobacco smoking [15].
Loneliness is a significant biopsychosocial stress factor and although the correlations between loneliness, obesity and metabolic disorders are poorly studied, more recent research indicates that loneliness is associated with obesity and stress in obese people [16].

\section{Conclusions}

The patients' age did not present a significant correlation with perceived stress score (PSS) values.The study results proved that the perceived stress score has not a significant prediction on LDL-cholesterol values and cardiovascular risk score (SCORE). The perceived stress level significantly influenced the glycosylated hemoglobin value, the fasting glycemia level and it is significantly higher in female patients. Aspects revealed by study results highlight the need for monitoring stress factor in actions of clinical management in patients at high cardiometabolic risk.

\section{References}

1. KANNEL, W.B., DAWBER, T.R., KAGAN, A., REVOTSKIE, N., STOKES, J.I. Ann. Intern. Med., 1961, 55, p. 33.

2.*** WHO Press. Global health risks: mortality and burden of disease attributable to selected major risks. WHO LibraryCataloguing-inPublication Data. ISBN: 978-92-4-156387-1 (NLM classification: WA 105). 3. YUSUF, S., HAW KEN, S., OUNPUU, S., et al. Lancet, 2004, 364, p. 937. 4. BEKLEY, E.T. DOC News, 3, 2006, p. 1.

5. HANCU N, CERGHIZAN A. Global Approach to Cardiovascular Risk în Type 2 Diabetic Persons. In: HÂNCU N. (Editor): Cardiovascular Risk în Type 2 Diabetes Mellitus. Berlin, Heidelberg, New York: Springer-Verlag, 2003, p. 240-276.

6. DESPRES, J.P., BREWER, H.B. Eur. Heart J. Suppl. 2008, 10B, B1-B3. 7. COHEN, S., KAMARCK, T., MERMELSTEIN, R. J. Health Soc. Behav. , 24, 1983, p. 385.

8. GOLBIDI, S., FRISBEE, J.C., LAHER, I. Amer. J. Physiol. - Heart Circulat. Physiol., 308, 2015, 12, p. H1476.

9. LJUBOTINA, A., et al. Collegium antropologicum, 38, 2014, 4, p. 1179.

10. TUCKER, P., et al. Chronobiology Internat.,29, 2012, 5, p. 549.

11. AL-DAGHRI, N.M., et al. BMC Public Health, 14, 2014, 1, p. 1.

12. DE VENTE, W., et al. BioMed. Res. Int., 2015:431725.

13.BERGMANN, N. C., FINN, G., J ENS, F. Endocrine connections, 2014, EC-14.

14. REDMOND, N., et al. J. Amer. Heart Assoc., 2, 2013, 6, e000447.

15. GALLO, L.C., et al. Psychosomatic medicine, 76, 2013, 6, p.468. 16. PETITTE, T., et al. The Open Psychol. J., 8, Suppl 2, 2015, p. 113.

Manuscript received: 22.07 .2018 